\title{
XII. On the best means for conducting meteorological observations in different places and climates, so as to produce some uniformity in the modes of obtaining and summing up the results
}

\section{Luke Howard Esq.}

To cite this article: Luke Howard Esq. (1821) XII. On the best means for conducting meteorological observations in different places and climates, so as to produce some uniformity in the modes of obtaining and summing up the results, Philosophical Magazine Series 1, 57:274, 81-83, DOI: 10.1080/14786442108652463

To link to this article: http://dx.doi.org/10.1080/14786442108652463

曲 Published online: 27 Jul 2009.

Submit your article to this journal $\pi$

Џll Article views: 4

$Q^{\mathbf{2}}$

View related articles $₫$ 


\section{$\left[\begin{array}{ll}81 & 1\end{array}\right.$}

XII. On the lest Means for conducting meleorological Olservations in different Places and Climates, so as to produce some Uniformity in the Modes of oltaining and summing up the Results. By Luke Howard, Esg.

\section{To Mr. Tilloch.}

My old aAid respected Friend, - I Have to thank thee for the care and delivery of a letter on Meteorological Subjects, addressed to me from Italy; and in doing this to claim a little space in the pages of the Philosophical Magazine, so often usefully devoted to this branch of science, for the purpose of giving publicity both to the most material parts of the letter, and to a few observations I shall have to make upon it, and which I have no doubt will by this means promptly reach its author.

The gentleman who favours me with this cominunication, and who subscribes himself "Castellani, Inspecteur dans le Corps de Pouts et Chaussées à Turin," has been led by the duties of his profession to pay a regular attention to meteorological observatious; and in attempting to compare his own with those of other observers, in distant climates, has been stopped by the obstacle so generally experienced by the cultivators of this infant science, the variety which prevails in the mode of oblaining and summing up results. As it is not at all probable that men of science in different countries will long continue to submit to the glaring absurdity of being thus, as it were, barbarians to each other, in a branch of their common pursuits which promises, by due culture, to become both fruitful and respectable, 1 think it but justice to this gentleman here to state the principles on which he thinks the common system should be founded: which are these:

The Meteorological year to begin with the vernal equinox: by this means, the six summer months are made to form the first division, and the six winter months the second; for the purpose doubtless, though he does not mention it, of contrasting the mean temperature, rain, \&c. of the two setsons; and of each of them with the same in other years.

The subdivisions to be of ten days each. The author thinis a mean result founded on the monil comprehends too many of the daily observations, and that of the week, too few; while results taken on every ten days would, in his opinion, give the course of temperature, in particular, in a more perspicuous manner. Each of the four seasons in this case would consist (with the necessary intercalary additions) of nine decades of days.

A more important object still with him is, the proper division of the day of 24 hours: for he thinks we lose much in maling Vol. 57. No.274. Fel. 1821. 
our observations relate to the whole of that space; which he would therefore divide into four equal parts, to each of which a set of observations should distinctly relate. I suppose, in order to obtain far better comparison, the heat of the day, the cold of the night, and the two intervening spaces of middle temperature, as also the duration of other phænomena, with reference to these four periods. He deprecates the objection of making the observations by this means too laborious, though it is clear, that only persons of fixed or sedentary habits could comply with such a rule; which for that reason it would not be advisable to make a general one.

With regard to the variations of the barometer and thermometer, he thinks that, for want of knowing the elevation of the place above the sea in the former case, and its annual mean temperature in the latter, we are often at a loss duly to appreciate the absolute measures, usually given of the height of each in the scale: he would therefore have the variations all put down relatively; that is, the barometer at such a time so many tenths plus or minus, with reference to a fixed mean height; and the temperature in like manner so many degrees plus or minus, with reference to a given mean temperature. This method would accord perfectly well with the mode of expressing the variation by curves, of which I gave a specimen, with a view to a particular object many years since, in the Philosophical Magazine ${ }^{*}$; and which I have since applied nore extensively in the second volume of the Climate of London. But, before it can be brought into successful practice for any given station, we must have for that station a sufficient series of observations with good instruments to enable us to fix pretty accurately its local mean, as to both instruments; which being obtained, such plus and minus results would speak a very intelligible language, and in the case of curves being used with a given scale, an universal one.

The writer of the letter proceeds to observe, that the mean temperature of a year, taken as a whole, has a certain influence in its productiveness in an agricultural sense; but that the $i r$ regular distribution of the heat, even in a warm year, may render it a barren one. To pursue the inquiry into this interesting part of the subject, he views the day whether in winter or suminer as warm or cold, with reference to the mean heat of the decade in which it stands; a method which may sometimes give more warm days in the winter than in the summer half year.

In order to the establisiment of a common mode of graduation in meteorological instruments, he proposes that decimal divisions of the scale be adopted in all cascs. As he employs

* Vol. vii. p. 365, \&c.

Six's 


\section{Olservations in different Places and Climates.}

Six's thermometer, which is commonly graduated by Fahrenheit's method, he must have new modelled the scale to his purpose. On the whole, I must refer this gentleman, and the readers of the Philosophical Magazine in general, to the work I have already mentioned, for much that might be here said in reference to the contents of this letter, the inost material part of which I have extracted. It may be observed, as a general proposition, that nothing is likely to be gained by departing from the ordinary mode of publishing Meteorological Tables every month. The European calendar is equally applicable in all parts of the globe; but seasons differ, and are even reversed by the position of the place of observation in another hemisphere. About the polar circle, again, they have a long severe winter and a short warm summer, without spring or autumn: within the tropics, two seasons which approach more nearly in their character to a wet spring and a dry attumn, both indeed at a temperature much higher than we experience in these middle latitudes. As the four seasons exist only in these, it is here alone that they can be compared in the method proposed: other modes must be adopted for the hot and cold climates, and it is nearly indifferent in what portions the observations are produced, provided the method of summing up the results be properly adapted to the climate, the natural divisions of which should in every case be studied and adhered to. There is, I think, much merit in the specimen given by M. Castellani, of his method, in the Billiotheque Universelle* : but to me, who have seen it for the first time only within these few days, the same difficulty presents itself in attempting to compare it with my own, of which he complains-a new method and new measures to be studied and comprehended, before the matter can be come at for the intended use. The use of curves (I repeat it as being the most essential part of my letter) for the purpose of expressing every thing in meteorology that is sulject to measures, would do away at once so much of this difficulty, as to render it easy to proceed in common with our respective observations, and compare them in detail, as well as in result, at a glance; at least until the great object of a uniform mensure for all civilized nations be satisfactorily accomplished. The data in figures should however in this case be required alung with the graphical representations, or should at least be kept in readiness to be produced as vouchers of their accuracy.

Tottenham, $23 \mathrm{~d}$ of first month, 1821 .

$$
\text { I am respectfully thy friend, }
$$

* Vol. ii. p. 232, 1819.

LUKE Howard. 